\title{
Loss of USP18 in microglia induces white matter pathology
}

\author{
Marius Schwabenland 1 , Omar Mossad ${ }^{1,2}$, Adam G. Peres ${ }^{1}$, Franziska Kessler ${ }^{1}$, Feres Jose Mocayar Maron', \\ Laura-Adela Harsan ${ }^{3,4}$, Thomas Bienert ${ }^{3}$, Dominik von Elverfeldt ${ }^{3}$, Klaus-Peter Knobeloch ${ }^{1}$, Ori Staszewski ${ }^{1}$, \\ Frank L. Heppner ${ }^{5,9,10}$, Marije E. C. Meuwissen ${ }^{6}$, Grazia M. S. Mancini ${ }^{6}$, Marco Prinz ${ }^{1,7,8}$ and Thomas Blank ${ }^{1 *}$ (D)
}

Keywords: Microglia, Type I interferon, Usp18, White matter, Phagocytosis, Corpus callosum, Behavior, Magnet resonance spectroscopy, Microgliosis

\section{Main text}

Ubiquitin specific protease 18 (USP18) is a major negative regulator of the type 1 interferon (IFN) pathway. In a recent publication we showed that USP18 is a key molecule imposing microglial quiescence specifically in the white matter [7]. USP18 is a negative regulator of the type 1 interferon (IFN) pathway [9]. Microglia lacking Usp18 exhibited constitutive activation of type I IFN signaling pathways resulting in markedly elevated expression of multiple interferonstimulated genes (ISGs) [7]. Additionally, Usp18-deficient brains exhibited clusters of microglia in the white matter that strongly resembled the neuropathological state in several human microgliopathies. Human diseases in which microgliopathies play a primary role comprise Nasu-Hakola disease [14], hereditary diffuse leukoencephalopathy with spheroids (HDLS) [15] and Pseudo-TORCH syndrome (PTS), including Aicardi-Goutières syndrome [12]. One might speculate that activated microglia in the white matter induce white matter abnormalities with functional consequences. However, there were no cells which had taken up myelin in young adult mice as seen by luxol fast blue-PAS (LFB-PAS) histology (unpublished data). Myelin uptake by other cells, like macrophages, would have been indicative of myelin damage. That is why we now characterized conditional myeloidspecific Usp18 deficient mice in more detail.

We know that Usp18 transcripts are highly expressed in unstimulated white matter microglia with only negligible expression levels in other CNS cells [7]. In a

\footnotetext{
*Correspondence: thomas.blank@uniklinik-freiburg.de

${ }^{1}$ Institute of Neuropathology, Faculty of Medicine, University of Freiburg,

Breisacher Str. 64, 79106 Freiburg, Germany

Full list of author information is available at the end of the article
}

previous study, we have confirmed by PCR analysis that $C x 3 c r 1^{\text {Cre }}:$ Usp $18^{\text {fllfl }}$ mice have an Usp 18 deletion in microglia but not in neuroectodermal cells of the CNS. These mice displayed a significant increase of $\mathrm{Iba}^{+}$ microglia cell numbers in several white matter regions including the corpus callosum as young adult mice [7]. This microgliosis persisted with increasing age and was detectable even in 4- and 8-month old mice (Fig. 1a, b). Usp18-deficient microglia exhibit constitutive expression of IFN target genes and fail to downregulate IFNinduced genes because the termination of type I IFN signaling is severely impaired. This became evident by the increase in ISG15 positive cells in the corpus callosum (Fig. 1a, b) and the elevated phosphorylation of STAT1 in Usp18-deficient microglia when compared to Usp $18^{f l / f l}$ mice (Fig. 1c). We next investigated animals at later ages than before by immunostainings against lysosomeassociated membrane protein-2 (LAMP2) as a marker of phagocytosis [4]. We found increased LAMP2 positive signals in microglia, which were localized in the corpus callosum of $C x 3 c r 1^{C r e}: U s p 18^{f l / f l}$ mice at an age of 4 months (Fig. 2a, b) and 8 months (Fig. 2c, d). To analyze white matter integrity, we performed high-resolution (11.7 T) diffusion tensor imaging (DTI). We calculated the fractional anisotropy (FA) values, permitting an exploration of the orientation coherence of axons in this fiber bundle. We found that the FA values were reduced in the corpus callosum, the internal and external capsule of $\mathrm{Cx} 3 \mathrm{crl}{ }^{\mathrm{Cre}}$ : Usp $18^{f l / f l}$ mice (cf. Usp $18^{f l / f l}$ controls), suggesting diminished structural integrity of the white matter in 4- and 8month old animals (Fig. 2e). Additionally, we found increased numbers of cells that had incorporated myelin

(c) The Author(s). 2019 Open Access This article is distributed under the terms of the Creative Commons Attribution 4.0 International License (http://creativecommons.org/licenses/by/4.0/), which permits unrestricted use, distribution, and reproduction in any medium, provided you give appropriate credit to the original author(s) and the source, provide a link to the Creative Commons license, and indicate if changes were made. The Creative Commons Public Domain Dedication waiver (http://creativecommons.org/publicdomain/zero/1.0/) applies to the data made available in this article, unless otherwise stated. 


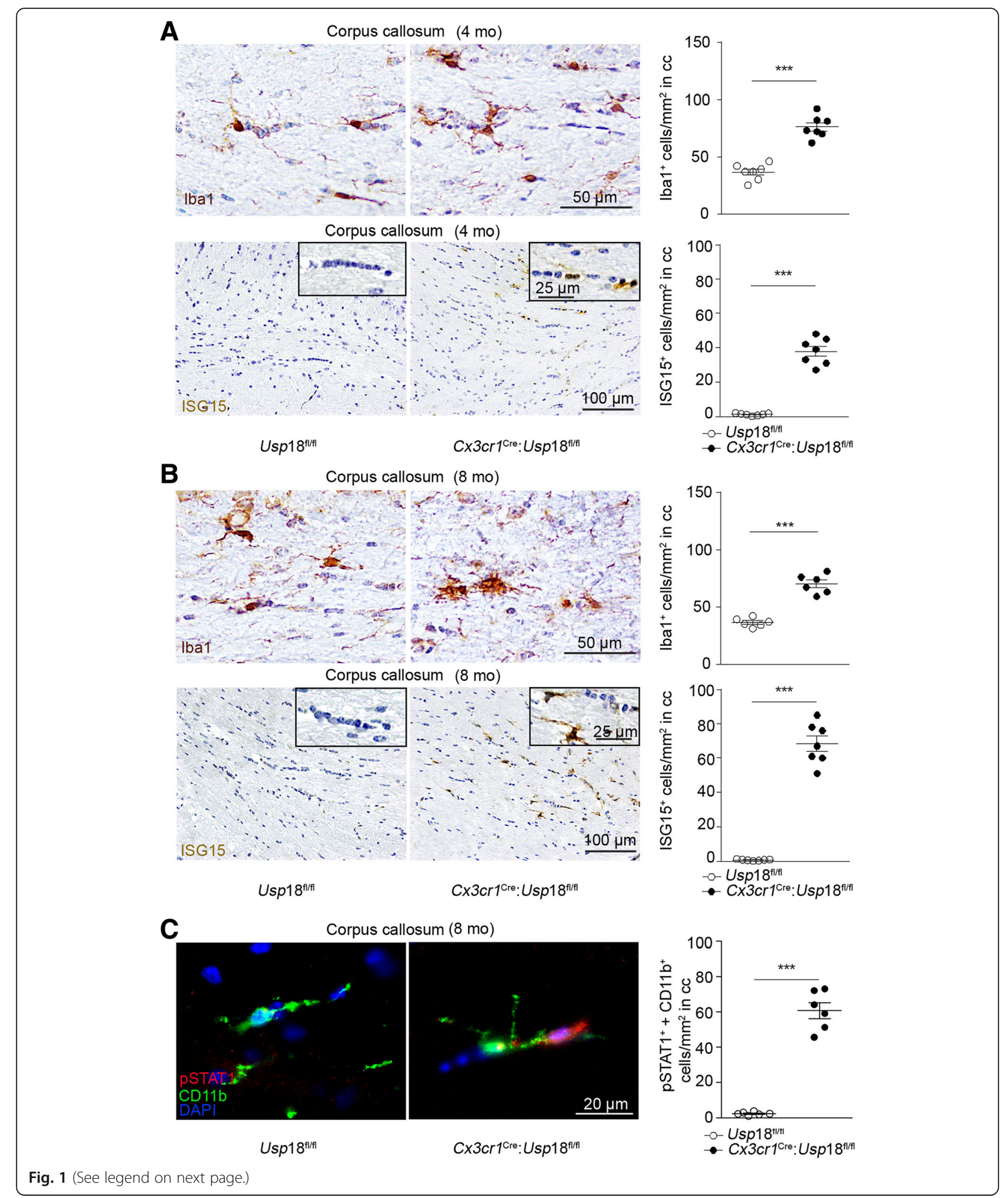


(See figure on previous page.)

Fig. 1 Microgliosis in corpus callosum of $C \times 3 \mathrm{Cr}^{\mathrm{Cre}}:$ Usp $18^{\mathrm{fl} / \mathrm{fl}}$ mice. $\mathbf{a}$, b Histology of corpus callosum in the cerebrum of adult Usp $18^{f / / f l}$ and CX3Cr1 ${ }^{\mathrm{Cre}}$ Usp $18^{\mathrm{flfl} / \mathrm{m}}$ mice at 4 (a) and 8 months of age (b). Primary antibodies against Iba1 and ISG15 were used. To quantify the number of Iba $1^{+}$or ISG $15^{+}$cells at least six mice per genotype and 5 sections per mouse from two independent experiments were counted. Quantification of cells is shown next to the respective histological images. Significant differences were determined by an unpaired $t$-test or Mann-Whitney U-test and marked with asterisks ( ${ }^{* *} P<0.001$ versus control littermates). Bars represent means \pm S.E.M. Scale bars $=25 \mu \mathrm{m}, 50 \mu \mathrm{m}, 100 \mu \mathrm{m}$. c Immunohistochemistry for

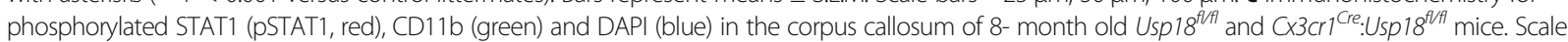
bar: $20 \mu \mathrm{m}$. Quantification of pSTAT1 ${ }^{+} \mathrm{CD} 11 \mathrm{~b}^{+}$cells is shown next to the respective histological images. Each symbol represents one mouse. Error bars represent S.E.M. Significant differences are determined by an unpaired $t$-test and marked with asterisks $\left({ }^{* * *} P<0.001\right)$
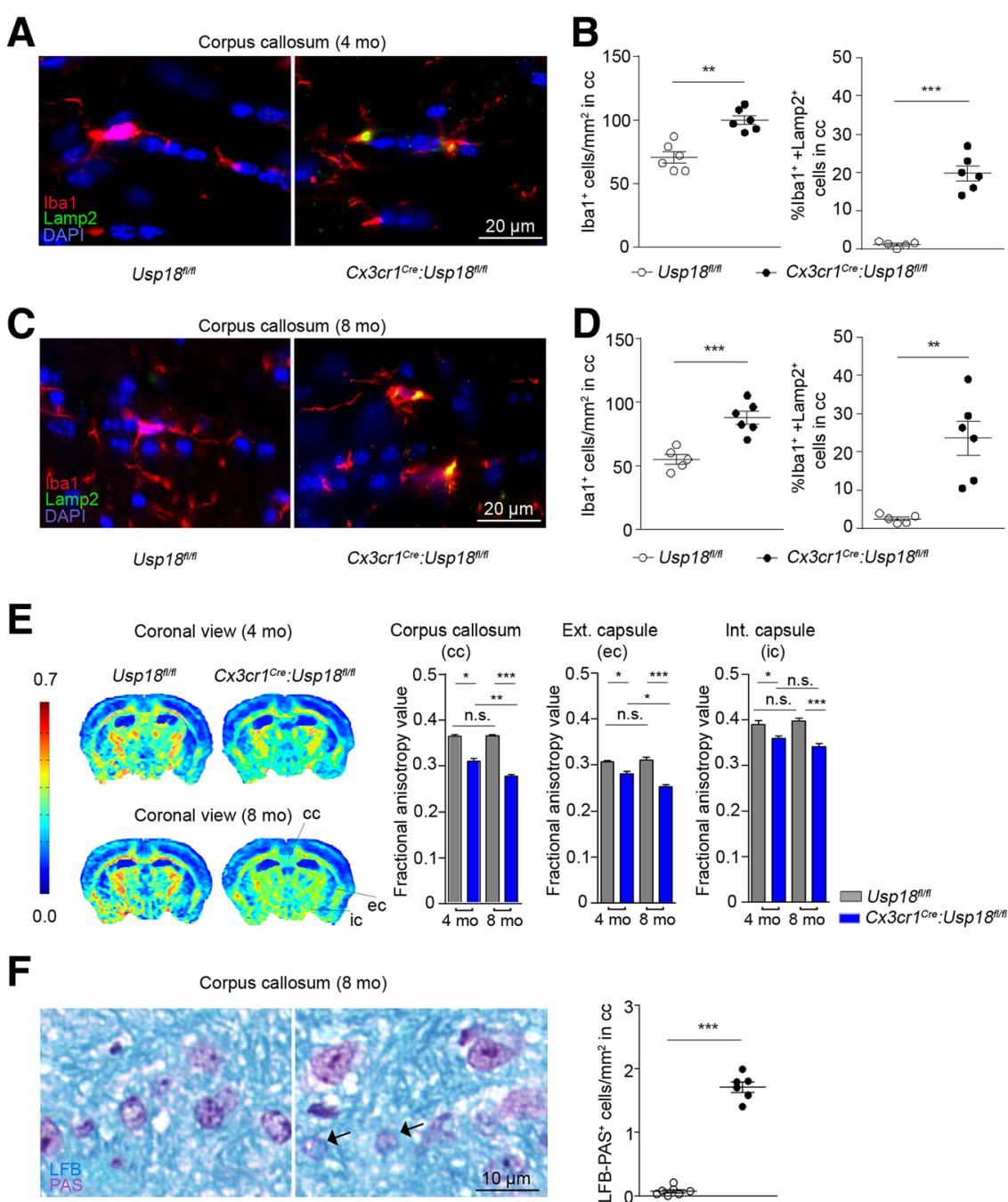

Usp18 $18^{\text {t/m }}$

CX3cr1 ${ }^{\text {cre }}:$ Usp $18^{\text {frf }}$
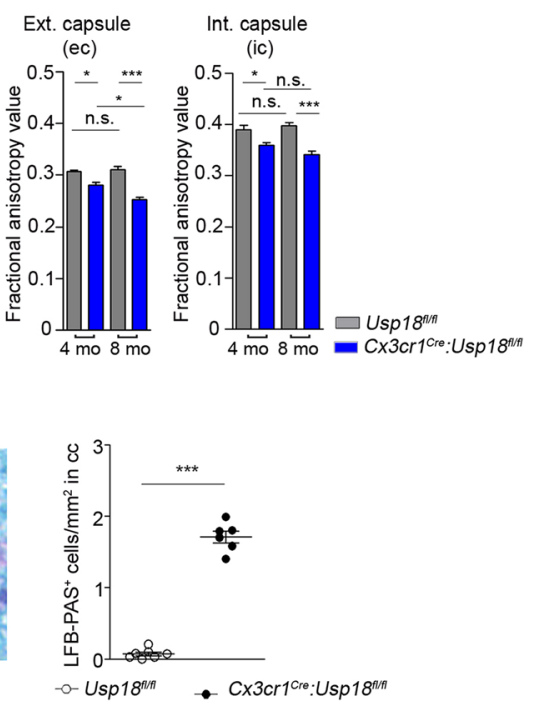

Fig. 2 USP18-deficient microglia reduces structural integrity in corpus callosum. a Immunofluorescent histochemistry for Iba1 (red), Lamp2 (green) and DAPI

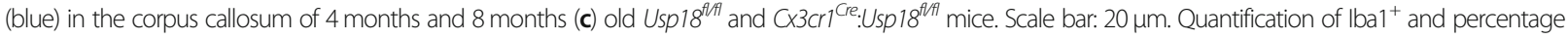
of Iba1 ${ }^{+}$Lamp2 ${ }^{+}$cells is shown next to the respective histological images (b, $\left.\mathbf{d}\right)$. Each symbol represents on mouse. Error bars represent s.e.m. Significant differences are determined by an unpaired $t$-test and marked with asterisks $\left.{ }^{* *} P<0.01,{ }^{* * *} P<0.001\right)$. e DTI was performed on 4 and 8 months old Usp $18^{A / f / t}$ and $\mathrm{C} \times 3 \mathrm{Cr}^{\mathrm{Cr}}$ :Usp $18^{\mathrm{At} / \mathrm{f}}$ mice to measure the FA of the corpus callosum. Tensor images were collectively acquired in several horizontal planes from +2.0 to $-4.0 \mathrm{~mm}$

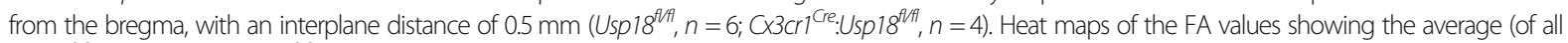
Usp $18^{A / f t}$ and $\mathrm{C} \times 3 \mathrm{Cr}^{\mathrm{Cre}}:$ Usp $18^{\mathrm{ft} / \mathrm{f}}$ animals) of one plane from each group (from anterior to posterior). Warm colors indicate fiber tracts with strong diffusion coherence. For both age groups the FA values were significantly reduced in $\mathrm{Cx} 3 \mathrm{cr} 7^{\mathrm{Cre}}: \mathrm{Usp}_{\mathrm{sp}} 18^{\mathrm{f} / \mathrm{f} / \mathrm{f}}$ mice in comparison to Usp $18^{\mathrm{f} / \mathrm{f}}$ mice. Approximate locations of the regions of interest (ROls) are indicated. Data are means \pm SEM. ( ${ }^{*} P<0.05$, ${ }^{* *} P<0.01$, ${ }^{* *} P<0.001$, n.s. $=$ non-significant). Statistical significance was determined using multiple $t$ tests corrected for multiple comparisons using the Holm-Sidak method with $a=0.05$. $\mathbf{f}$ Histological analysis by luxol fast blue-PAS

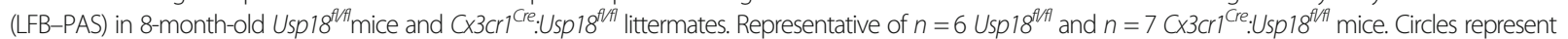
individual mice. Unpaired two-tailed t-test 
and thereby indicate damage to the myelin sheaths (Fig. 2f). Together, these findings point to a reduction in myelination or even to a loss of fibers in $C x 3 c r 1^{C r e}: U s p 18^{f l f l}$ mice $[2,17]$.

Deterioration of white matter tracts, affecting brain structural (SC) and functional connectivity (FC) is often paralleled by behavioral declines $[3,6,8]$. We therefore tested $C x 3 c r 1^{C r e}: U_{s p} 18^{f l / f l}$ mice and Usp18 $8^{f l f l}$ littermate controls in different behavioral paradigms. While mice lacking Usp18 in microglia performed normal in the odor avoidance test at 4 months of age (Fig. 3a), 8-month old $C \times 3 c r 1^{C r e}: U s p 18^{f l / f l}$ mice showed severely impaired olfaction (Fig. 3d). Similarly, learning and recognition memory was fully intact at 4 months of age (Fig. $3 \mathrm{~b}$ ) but decreased when $C x 3 c r 1^{C r e}: U s p 18^{f l f l}$ mice were 8-month old compared to age-matched $U_{s p} 18^{f l / f l}$ control mice (Fig. 3e). Rotarod performance, which measures motor coordination and motor learning, was also significantly impaired in 8month old $\mathrm{Cx} 3 \mathrm{cr} 1^{\mathrm{Cre}}:$ Usp $18^{\text {fllfl }}$ mice (Fig. 3f) with no deficits in 4 months old mice (Fig. 3c). In addition to the indicated mouse model we investigated brainstem tissue samples from three PTS patients with loss-of-function recessive mutations of USP18 [12]. Immunohistochemistry showed increased STAT1 phosphorylation in microglia of PTS patients when compared to age-matched control tissue (Fig. 4a). In patients' material there were also more microglial cells, which engulfed cells positive for Nogo-A (Fig. 4b), which represents an oligodendroglial marker [11].

The data presented here indicate that in myeloidspecific Usp18 knockout animals, microglia in the white matter were not only activated, but also caused advancing damage to this structure with subsequent behavioral impairment of the animals. USP18-deficiency in humans belongs to a group of genetic disorders that are collectively termed type I interferonopathies. These disorders are first characterized by the persistent upregulation of type I interferon signaling [16]. There have been at least seven possible cellular mechanisms described, which result in sustained activation of interferon signaling [16]. One of them, PTS, is a group of not so well-defined genetic diseases, which can originate from USP18 deficiency. We found that microglia in PTS patients displayed not only enhanced type I IFN signaling, but also close contact to oligodendroglia. A direct interaction might indicate that activated microglia, as suggested by their focally elevated cell density together with altered morphological properties inflict damage to oligodendroglia. This strongly resembles the white matter damage observed in $C x 3 c r 1^{C r e}: U s p 18^{f l / f l}$ mice. Type I interferon can be regarded as a neurotoxin if its levels are not tightly controlled. Accordingly, experiments undertaken in mice demonstrate that overexpression of

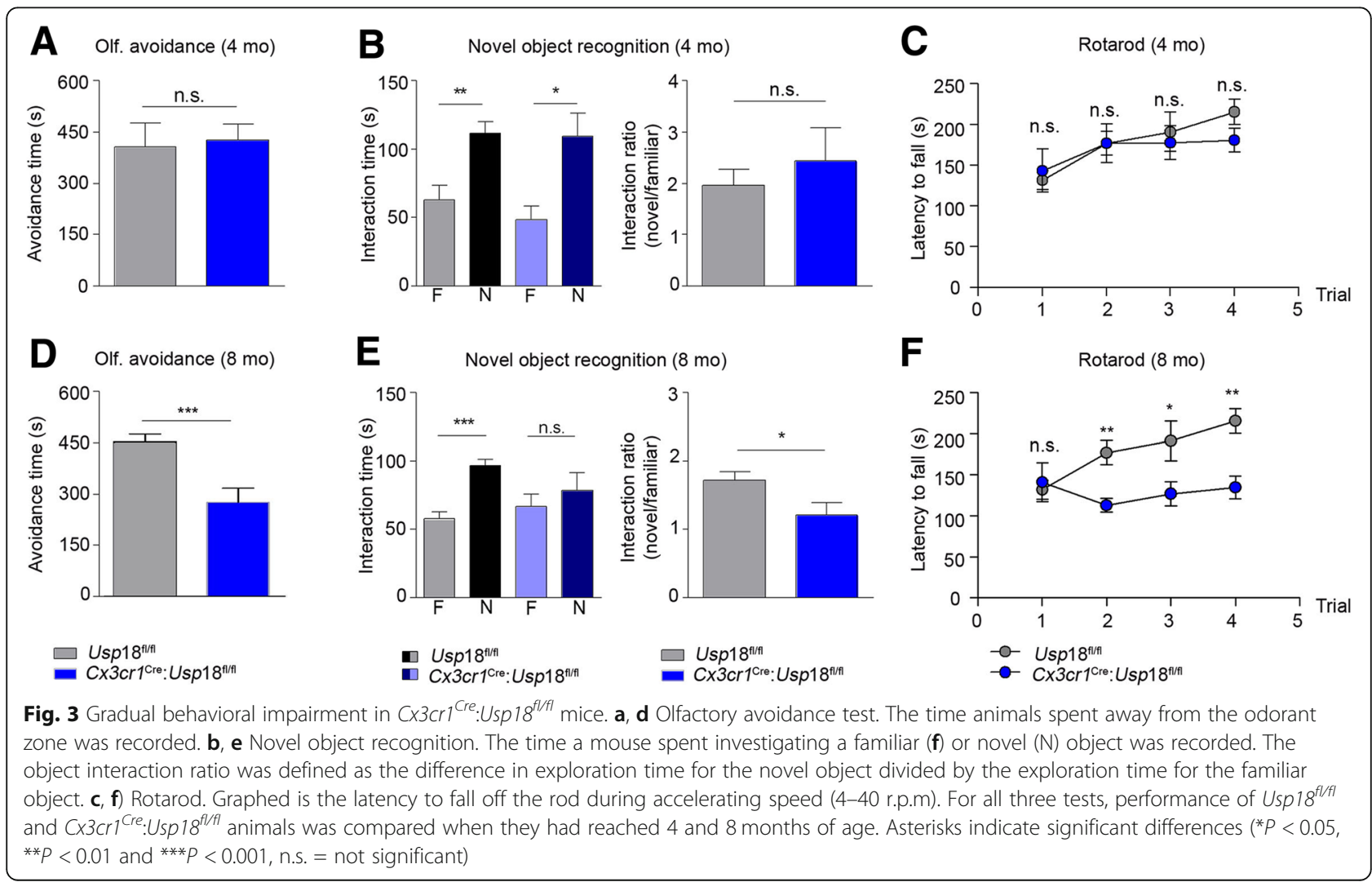



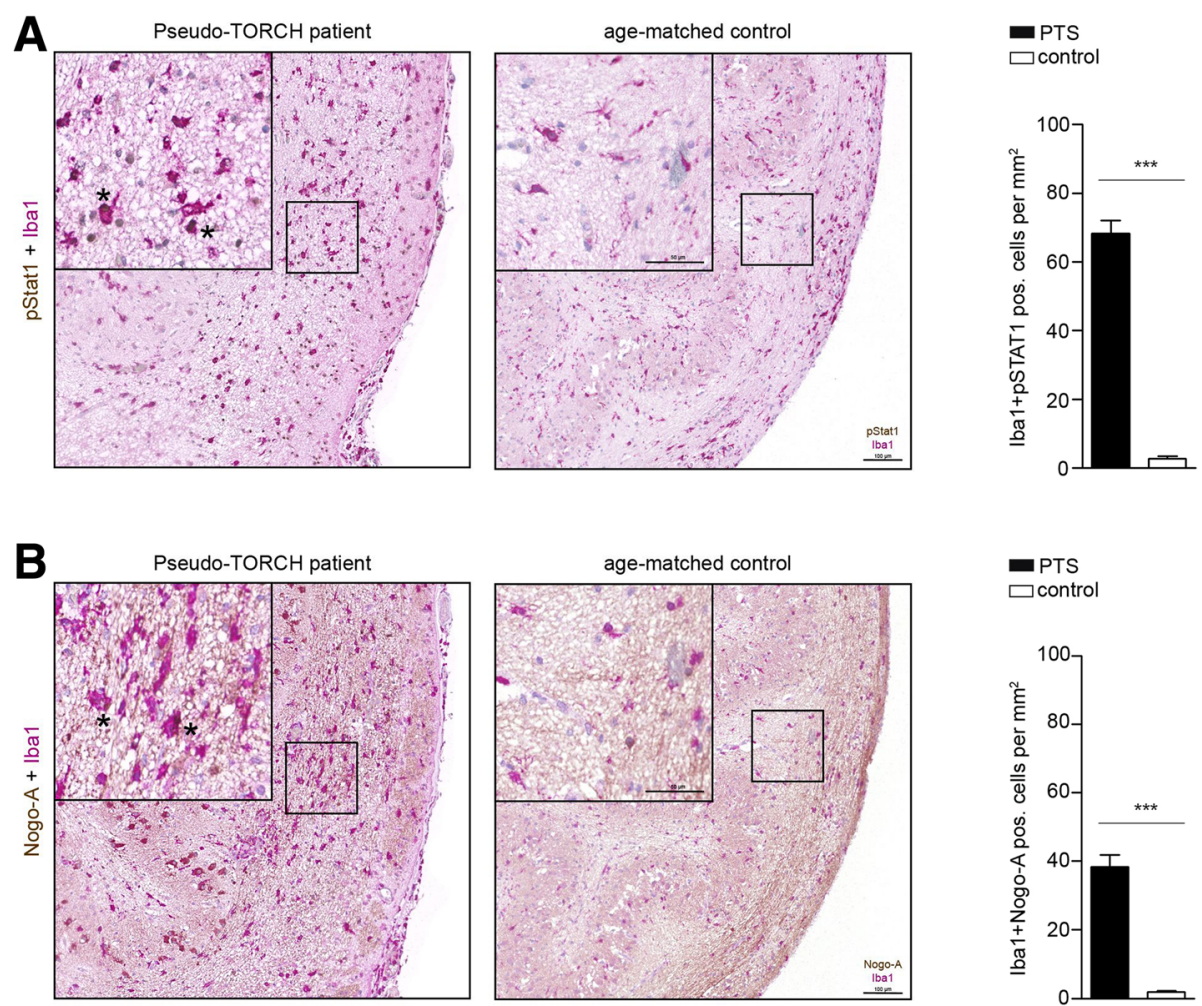

Fig. 4 Microgliosis in white matter of Pseudo-TORCH patients. a Histology of white matter in Pseudo-TORCH patients $(n=3)$ and age-matched controls $(n=3)(\mathbf{b})$. Primary antibodies were used against Iba1, pStat1 and Nogo-A. Quantification of cells is shown next to the respective histological images. Significant differences were determined by an unpaired $t$-test or Mann-Whitney U-test and marked with asterisks $(* * * P<0.001$ versus controls). Bars represent means \pm s.e.m. Scale bars $=50 \mu \mathrm{m}, 100 \mu \mathrm{m}$

interferon in the CNS results in neuropathology reminiscent of that seen in certain type I interferonopathies $[1,10]$. In the case of PTS, but also in the case of type I IFN overexpression, damage to the white matter seems to be prevalent $[5,12]$. It is still unclear what the type I IFN source is in the context of interferonopathies. Likewise it is enigmatic which signals are responsible for microglia activation in the white matter. The escalating spiral of white matter damage might be initiated by type I IFN that is induced in microglia via stimulator of interferon genes (STING), and this IFN likely influences the microglial phenotype in an autocrine and paracrine fashion [13].

The white matter specificity of the USP18 effect on microglia is of particular interest and further developments in this area may have implications for an entire range of neurological disorders in which there is a preponderance of white matter pathology.

\section{Abbreviations}

DTI: Diffusion tensor imaging; IFN: Interferon; ISG: Interferon-stimulated gene; MRI: Magnetic resonance imaging; NOR: Novel Object Recognition; PTS: Pseudo-TORCH syndrome; RT: Room temperature; STAT1: Signal transducer and activator of transcription 1; STING: Stimulator of interferon genes; USP: Ubiquitin-specific protease

\section{Acknowledgements}

The authors are thankful to Margarethe Ditter for excellent technical assistance.

\section{Authors' contributions}

TB, KPK, MECM, GMSM, OS, FLH and MP were responsible for the conception and design of experiments; TBi, LAH and DvE were responsible for MRI measurements; MS, OM, FK, AP and FJMM performed experiments, analysed and interpreted the data, they drafted the paper and revised and edited the final article. All authors read and approved the final manuscript.

\section{Funding}

TB was supported by the DFG (BL 1153/1-2). TB and MP are supported by the DFG (SFB/TRR167 "NeuroMac").

\section{Availability of data and materials}

The datasets used and/or analysed during the current study are available from the corresponding author on reasonable request.

\section{Ethics approval and consent to participate}

All animal experiments were approved by the Federal Ministry for Nature, Environment and Consumers' Protection of the state of Baden-Württemberg (G12/71; G16/107) and were performed in accordance with the respective national, federal and institutional regulations. For patients' samples written parental consent was obtained. Genetic tests were performed according to The Erasmus University Medical Center's local ethics board approved protocol MEC-2012387.

\section{Consent for publication}

All the authors have approved publication.

\section{Competing interests}

The authors declare that they have no competing interests. 


\section{Author details}

'Institute of Neuropathology, Faculty of Medicine, University of Freiburg, Breisacher Str. 64, 79106 Freiburg, Germany. ${ }^{2}$ Faculty of Biology, University of Freiburg, Freiburg, Germany. ${ }^{3}$ Department of Radiology, Medical Physics, University Medical Center Freiburg, Faculty of Medicine, University of Freiburg, Freiburg, Germany. ${ }^{4}$ Engineering Science, Computer Science and Imaging Laboratory (ICube), Integrative Multimodal Imaging in Healthcare, CNRS, University of Strasbourg, Strasbourg, France. ${ }^{5}$ Department of Neuropathology, Charité - Universitätsmedizin Berlin, corporate member of Freie Universität Berlin, Humboldt-Universität zu Berlin, and Berlin Institute of Health, Charitéplatz 1 (Virchowweg 15), 10117 Berlin, Germany. ${ }^{6}$ Department of Clinical Genetics, Erasmus University Medical Center, 3015, GD, Rotterdam, the Netherlands. ${ }^{7}$ Signalling Research Centres BIOSS and CIBSS, University of Freiburg, Freiburg, Germany. ${ }^{8} \mathrm{Center}$ for NeuroModulation, Faculty of Medicine, University of Freiburg, Freiburg, Germany. ${ }^{9}$ Cluster of Excellence, NeuroCure, Charitéplatz 1, 10117 Berlin, Germany. ${ }^{10}$ German Center for Neurodegenerative Diseases (DZNE) Berlin, 10117 Berlin, Germany.

Received: 16 May 2019 Accepted: 20 June 2019

Published online: 04 July 2019

\section{References}

1. Akwa Y, Hassett DE, Eloranta ML, Sandberg K, Masliah E, Powell H, Whitton JL, Bloom FE, Campbell IL (1998) Transgenic expression of IFN-alpha in the central nervous system of mice protects against lethal neurotropic viral infection but induces inflammation and neurodegeneration. J Immunol 161: 5016-5026

2. Basser PJ (1995) Inferring microstructural features and the physiological state of tissues from diffusion-weighted images. NMR Biomed 8:333-344

3. Bells S, Lefebvre J, Prescott SA, Dockstader C, Bouffet E, Skocic J, Laughlin S, Mabbott DJ (2017) Changes in white matter microstructure impact cognition by disrupting the ability of neural assemblies to synchronize. J Neurosci 37:8227-8238. https://doi.org/10.1523/JNEUROSCI.0560-17.2017

4. Blank T, Goldmann T, Koch M, Amann L, Schon C, Bonin M, Pang S, Prinz M, Burnet M, Wagner JE et al (2017) Early microglia activation precedes photoreceptor degeneration in a mouse model of CNGB1-linked retinitis Pigmentosa. Front Immunol 8:1930. https://doi.org/10.3389/fimmu.2017.01930

5. Cuadrado E, Jansen MH, Anink J, De Filippis L, Vescovi AL, Watts C, Aronica E, Hol EM, Kuijpers TW (2013) Chronic exposure of astrocytes to interferonalpha reveals molecular changes related to Aicardi-Goutieres syndrome. Brain 136:245-258. https://doi.org/10.1093/brain/aws321

6. Filley CM, Fields RD (2016) White matter and cognition: making the connection. J Neurophysiol 116:2093-2104. https://doi.org/10.1152/jn.00221.2016

7. Goldmann T, Zeller N, Raasch J, Kierdorf K, Frenzel K, Ketscher L, Basters A Staszewski O, Brendecke SM, Spiess A et al (2015) USP18 lack in microglia causes destructive interferonopathy of the mouse brain. EMBO J 34:16121629. https://doi.org/10.15252/embj.201490791

8. Gullmar D, Seeliger T, Gudziol H, Teichgraber UKM, Reichenbach JR, Guntinas-Lichius O, Bitter T (2017) Improvement of olfactory function after sinus surgery correlates with white matter properties measured by diffusion tensor imaging. Neuroscience 360:190-196. https://doi.org/10.1016/j. neuroscience.2017.07.070

9. Honke N, Shaabani N, Zhang DE, Hardt C, Lang KS (2016) Multiple functions of USP18. Cell Death Dis 7:e2444. https://doi.org/10.1038/cddis.2016.326

10. Kavanagh D, McGlasson S, Jury A, Williams J, Scolding N, Bellamy C, Gunther C, Ritchie D, Gale DP, Kanwar YS et al (2016) Type I interferon causes thrombotic microangiopathy by a dose-dependent toxic effect on the microvasculature. Blood 128:2824-2833. https://doi.org/10.1182/blood-201605-715987

11. Kuhlmann T, Remington L, Maruschak B, Owens T, Bruck W (2007) Nogo-a is a reliable oligodendroglial marker in adult human and mouse CNS and in demyelinated lesions. J Neuropathol Exp Neurol 66:238-246. https://doi.org/ 10.1097/01.jnen.0000248559.83573.71

12. Meuwissen ME, Schot R, Buta S, Oudesluijs G, Tinschert S, Speer SD, Li Z, van Unen L, Heijsman D, Goldmann T et al (2016) Human USP18 deficiency underlies type 1 interferonopathy leading to severe pseudo-TORCH syndrome. J Exp Med 213:1163-1174. https://doi.org/10.1084/jem.20151529

13. Nazmi A, Field RH, Griffin EW, Haugh O, Hennessy E, Cox D, Reis R, Tortorelli L, Murray CL, Lopez-Rodriguez AB et al (2019) Chronic neurodegeneration induces type I interferon synthesis via STING, shaping microglial phenotype and accelerating disease progression. Glia. https://doi.org/10.1002/glia.23592
14. Paloneva J, Manninen T, Christman G, Hovanes K, Mandelin J, Adolfsson R, Bianchin M, Bird T, Miranda R, Salmaggi A et al (2002) Mutations in two genes encoding different subunits of a receptor signaling complex result in an identical disease phenotype. Am J Hum Genet 71:656-662. https://doi. org/10.1086/342259

15. Rademakers R, Baker M, Nicholson AM, Rutherford NJ, Finch N, SotoOrtolaza A, Lash J, Wider C, Wojtas A, DeJesus-Hernandez M et al (2011) Mutations in the colony stimulating factor 1 receptor (CSF1R) gene cause hereditary diffuse leukoencephalopathy with spheroids. Nat Genet 44:200205. https://doi.org/10.1038/ng.1027

16. Rodero MP, Crow YJ (2016) Type I interferon-mediated monogenic autoinflammation: the type I interferonopathies, a conceptual overview. J Exp Med 213:2527-2538. https://doi.org/10.1084/jem.20161596

17. Song SK, Sun SW, Ramsbottom MJ, Chang C, Russell J, Cross AH (2002) Dysmyelination revealed through MRI as increased radial (but unchanged axial) diffusion of water. Neuroimage 17:1429-1436

\section{Publisher's Note}

Springer Nature remains neutral with regard to jurisdictional claims in published maps and institutional affiliations.
Ready to submit your research? Choose BMC and benefit from:

- fast, convenient online submission

- thorough peer review by experienced researchers in your field

- rapid publication on acceptance

- support for research data, including large and complex data types

- gold Open Access which fosters wider collaboration and increased citations

- maximum visibility for your research: over $100 \mathrm{M}$ website views per year

At BMC, research is always in progress.

Learn more biomedcentral.com/submissions 